\title{
Debate
}

\section{The missions of medical schools: the pursuit of health in the service of society Ray M Lewkonia}

Address: University of Calgary, Faculty of Medicine, HMRB 112, 3330 Hospital Drive, NW Calgary, Alberta T2N 4N1, Canada

E-mail: rlewkoni@ucalgary.ca

Published: 18 October 2001

BMC Medical Education 200I, I:4
Received: 4 September 2001

Accepted: 18 October 2001

This article is available from: http://www.biomedcentral.com/1472-6920///4

(C) 200I Lewkonia; licensee BioMed Central Ltd. Verbatim copying and redistribution of this article are permitted in any medium for any non-commercial purpose, provided this notice is preserved along with the article's original URL. For commercial use, contact info@biomedcentral.com

\begin{abstract}
Mission statements and role documents of medical schools in the United Kingdom, United States, Canada and Australia have been examined on their Internet Web sites and categorised in purpose, content and presentation. The format and content are highly variable, but there is a common vision of three integral roles, namely, education, advancement of knowledge and service to society. Other frequent themes include tradition and historical perspective, service for designated communities, and benchmarking to accreditation standards. Differences in content reflect variable interpretation of the notion of "mission", and local or national characteristics such as institutional affiliations, the types, levels and organisation of medical education, relationships with health systems, and extent of multi-professional education. Outcomes data and measures of medical school performance referenced to the institution's stated missions are rarely encountered.

Mission documents placed on the Internet are in the public domain. These Web sites and documents and linked information constitute a valuable new resource for international exchange of approaches and ideas in medical education and generally in academic medicine. Routine inclusion of outcome or performance data could help to demonstrate the community roles and social accountability of medical schools This paper proposes that partial standardisation of these Web documents could enhance their value both internally and for external readers. A generic descriptive statement template is offered.
\end{abstract}

\section{Introduction}

The University of Aberdeen, Scotland records on its Web site [1] that the first academic chair of medicine in the English-speaking world was established in 1497 at King's College, Aberdeen with an original mission of the pursuit of health in the service of society. Five centuries later, in 1991 a group of distinguished medical academics from the United States, Canada, the United Kingdom, and Australia met under the sponsorship of the Royal Society of Medicine (RSM) Foundation and produced a report on the missions of medical schools [2]. This was promulgat- ed in the context of "a long-term implicit social contract that has existed between the medical establishment and the society that it serves". The first of five recommendations in the RSM report was that, in the interests of public accountability and professional service, each school should develop and publicize an institutional statement of mission, goals and objectives, to include strategies for evaluating progress towards the institution's objectives using population-based and individual outcomes. This and the other recommendations regarding faculty development, education and sensitivity to population health 
needs were intended to promote increased responsiveness to the expectations of stakeholders, that is social accountability. One decade later Internet technology has enabled medical schools to readily publicise their missions and institutional priorities in the public domain.

The mission documents from medical schools in the United Kingdom, United States, Canada, and Australia have been examined with regard to the aims of the schools in general and the content proposed in the RSM report with regard to social accountability.

\section{Methods}

The Internet Web sites of medical schools in the four countries were located from listings on the Web sites of accrediting bodies - the American Association of Medical Colleges (AAMC) [3] and the Liaison Council for Medical Education (LCME) [4], the Association of Canadian Medical Colleges (ACMC) [5], the General Medical Council (GMC) [6] and the Quality Assurance Authority (QAA) [7] of the United Kingdom, and the Australian Medical Council (AMC) [8]. The medical school Web sites were inspected for mission statements, and if these were not found, statements of philosophy or purpose or other similar documents were sought. Sometimes the mission was described in a dean's message or a strategic plan, in admissions policies or general curriculum outlines. The Web sites and the mission statements often have links to internal departmental sites, each with their own mission documents.

\section{Themes in mission statements}

All medical schools in the four countries have described their missions and related descriptive information on their Web sites, and it is notable that all of the Webbased presentations are different. Five general themes were noted in the presentation of mission documents, with more than one of these being included on many sites - tripartite responsibility, tradition and historical perspective, service for specified communities, benchmarking to templates of accrediting organisations, and (least often) performance and outcome data. Narrative examples are given in order of diminishing frequency:

\section{Tripartite responsibility}

Typical descriptive statements list the three realms of education, research and clinical service, usually in that sequence, sometimes with elaboration of the concepts:

The mission of the medical school is threefold: the training of physicians, the search for new knowledge, and the care of the sick. The three are inseparable. Medicine can be handed on to succeeding generations only by long training in the scientific methods of investigation and by the actual care of patients. (New York University School of Medicine)

Within the overall mission of the University, the purpose of the Faculty of Medicine and Health Sciences is to promote health, well-being and the highest quality of health care through excellence in education, research and professional practice. (Queen's University Faculty of Medicine and Health Sciences, Belfast, Northern Ireland).

Central to our mission is the preparation of health professionals and scientists who can contribute to humane and cost-effective health care, continue independent and efficient learning, adapt to change and initiate change, and collaborate within interdisciplinary teams. The Faculty of Health Sciences aspires to continued development as an institution of international stature. In fulfilment of our mission, we shall pursue: The development and critical evaluation of new knowledge about the biological, behavioural, social and environmental basis of health and disease; and about the usefulness of preventive, therapeutic and rehabilitation maneuvers (McMaster University Faculty of Health Sciences, Ontario, Canada).

\section{Tradition and historical perspective}

Long established schools are less likely to state an explicit mission, perhaps because it has been achieved, instead describing their history of service, their scientific reputation and distinction of their staff and graduates as leaders implying the expectation of future success for their students:

...known throughout the world as one of the leading centers for biomedical research, education and advanced health care. Founded in 1810, the School of Medicine has grown to include every modern medical discipline. Its faculty includes some of the world's most respected scholars in medicine, public health and biomedical science. (Yale University School of Medicine, Connecticut; instruction commenced 1810).

To provide international leadership in the education of physicians and medical scientists, in biomedical research, and in the application of medical knowledge to patient care. (Johns Hopkins University School of Medicine, Maryland; instruction commenced 1893) ... is the oldest medical school in Australia, being established in 1862. It attracts many of the best students in Australia, and for the last 10 years has attracted more research funding then any other medical school in Australia. This ensures the School attracts and maintains staff of the highest quality and that teaching is up-to-date and well informed by the latest research... The Faculty has an in- 
ternational reputation for leadership in teaching and research. Many graduates of the Faculty are leaders in their fields. In medicine graduates have included two Nobel Prize winners. (The School of Medicine, University of Melbourne, Australia; instruction commenced 1862)

In line with the mission of the University of Cambridge, the aims of the school are: to foster academic excellence and to provide an education of the highest quality so as to produce medical practitioners of the calibre sought by the professions, and in addition providing the teachers of the future. (Cambridge University, England; established 1453).

\section{Service for specified communities}

Delineation of populations supported by the medical school appears most often in the statements of young medical schools and those established in areas of relatively low population density. These service-orientated statements are more likely to mention other health professions and multi-professional service models:

The mission of the SIU School of Medicine is to assist the people of central and southern Illinois in meeting their health care needs through education, research, and service. (Southern Illinois University; instruction commenced 1970)

Our purpose is to enhance the health of the people of Newfoundland and Labrador by educating physicians and health scientists; by conducting research in clinical and basic medical sciences and applied health sciences and by promoting the skills and attitudes of lifelong learning. (Memorial University, Newfoundland; instruction commenced 1969).

Programs will be responsive to the health needs of the communities of northern Australia and the School will be a leader in the focus areas of rural and remote health, Indigenous health and tropical medicine for Australia and for the wider Asia-pacific region The School was established in recognition of the need for advancement of medical education and research relevant to the communities of northern Australia. (James Cook University School of Medicine, Australia; instruction commenced 2000).

Benchmarking to templates of accrediting organisations

This is seen particularly in the descriptive statements of British medical schools. Curricular design has been influenced throughout the U.K. by Tomorrow's Doctors, a 1993 publication of the GMC [9]. The most consistent organization of information was found in QAA documents in its first category entitled "aims and objectives" of the school. QAA reports relate to curricular structure and implementation, and do not deal with outcomes for graduates or populations. The effects of the QAA framework has been evident in school mission documents, for example:

....to be the leading Medical School in the UK as judged by such criteria as the outcomes of the HEFCE Research Assessment Exercise and the Quality Assessment of teaching. (Imperial College School of Medicine, London)

The School's mission is to promote by excellence in teaching, clinical practice and research the prevention, treatment and understanding of disease. In doing so we make special use of our opportunities to work closely with the National Health Service and of the interdisciplinary opportunities that we have. Scientists and medical students, doctors, nurses, psychologists, midwives, physiotherapists, radiographers and administrators are all important members of the St George's family. Our external reviews of teaching by the Quality Assurance Agency (QAA) have all been outstanding (23/24 for medicine). (Saint George's Hospital Medical School, London).

\section{Performance data and ratings}

Aggregate data on career paths is available in the Canadian Post-MD Education Registry [10]. Outcome information other than research success is not commonly given on individual medical school Web sites, and is selective:

The School of Medicine earned the annual Innovations to Curriculum Award from the American Medical Association, medical student section. The School of Medicine is ranked in the top 2 percent of American medical schools for its primary care education program for the fifth consecutive year as reported in U.S. News \& World Report. Of the 144 schools reported on, OHSU's primary care education program ranks third; family medicine education ranks fourth for the fifth consecutive year; and the specialty of rural medicine ranks 11th. Forty percent of the currently licensed physicians in Oregon have received their undergraduate and/or graduate medical education at OHSU. About 60 percent of graduating medical students choose primary care residencies, up from 40 percent 10 years ago. An impressive 96 percent to 100 percent of graduates in OHSU's M.D. program pass their licensure exams on the first attempt, a passing rate higher than the national average. (Oregon Heath Sciences University).

\section{Institutional structure}

The nature of the medical school is not always evident from the name of the institution, and they include: (a) 
graduate schools in research-orientated academic medical centres - most common in the U.S., (b) schools that train more than one type of health professional, administratively integrated with a university, (c) hospitalbased or community-based medical school affiliated with a university. Extracts from two Web sites illustrate examples of striking differences in conceptions of a "school" environment:

To support its mission of education research and patient care, the School has ......nearly 8,ooo faculty and 17 affiliated facilities. At the core of the Medical School are its educational and research programs. The student body is composed of 650 mean and women in the MD program; 477 students in the PhD program; and 132 in the joint MD:PhD program. (Harvard Medical School, Massachusetts).

Community based: nationally recognised ... as a community-based medical school EVMS does not own a teaching hospital. Instead EVMS works in partnership with hospitals, physicians and clinics throughout the region.... For the region as a whole, these educational partnerships spread the benefits of an academic medical center throughout the region, improving the quality of life and the quality of health care for the entire community. (East Virginia Medical School of the Medical College of Hampton Roads).

\section{The purpose and semantics of mission documents}

Mission statements have been defined for the (not-forprofit) health care sector in the United States as formal documents that attempt to capture an organization's unique and enduring purpose and practices [11]. Important functions include giving a sense of purpose, motivating employees to identify with the organisation, giving recognition to the interests of external stakeholders, and to improve the resource allocation process. Each of these could be translated to the medical school context. However, expression of the concept of "mission" for medical schools was found to be extremely variable in all four countries. Some Web sites have a succinct vision with brief elaboration and in others the mission is expressed in a large multi-part strategy document.

Although the formats vary, the mission documents generally use similar expressions in all four countries. Words are selected to convey great expectations of academic accomplishment for students and staff. Verbs are chosen that predict achievement, the nouns offer the promise of success, and the phrases look to the future. The wording speaks to institutional reputation, and the goals of attracting academically effective staff and good students to the school [12]. Examples of words used to characterize the capabilities of schools and the expecta- tions of qualities to be imbued into students are listed below:

\section{Institutional performance}

Advance, aim, aspire, build, develop, enable, encourage, ensure, expand, facilitate, foster, implement, lead, prepare, produce, provide, strive.

\section{Desirable attributes}

Commitment, compassion, excellence, highest standards, humanitarian or humanistic, innovation, leadership, life-long learning, outstanding, quality, self-reliant, strong.

\section{Discussion}

Universal goals of all medical schools are contained in the succinct Scottish version of the $15^{\text {th }}$ century: The pursuit of health in the service of society [1]. The actual wording with which this is expressed in later renditions is of less importance than the manner is which the goals are to be achieved. Beyond the style of prose and presentation, the Web sites portray the operation of individual medical schools, and provide some insight into structural differences. Details of curricula and educational governance in the majority of medical schools in the United States and Canada have been published [13]. Neither these outlines nor the public domain reports of the accrediting agencies conform with the mission document concept proposed in the RSM report that was used as a reference point for this study (Figure 1). Although the RSM report was not issued by an official organisation, its recommendations were authoritative and important. The documents that are available generally do not address the manner in which medical school outcomes are evaluated nor whether the schools' stated objectives have been attained, using individual and population-based outcomes. For example, if a medical school was established primarily to serve a particular population, it would be helpful for the public and similar schools to know how many graduates were actually in practice in that community several years after completion of training.

The accreditation processes in the four countries are important in determining the goals of medical schools. However, it is necessary to differentiate accreditation of medical education from assessment of medical schools in relation to their overall mission. Their achievements need to be framed in the expectations of the community or society that supports and funds the institution. To use an educational analogy, medical schools may demonstrate ability and competence in the test circumstances of accreditation, but the appropriate measures of outcome as fulfilment of objectives are evaluation of performance and quality. The intellectual significance of seeking outcomes information follows the proposition 


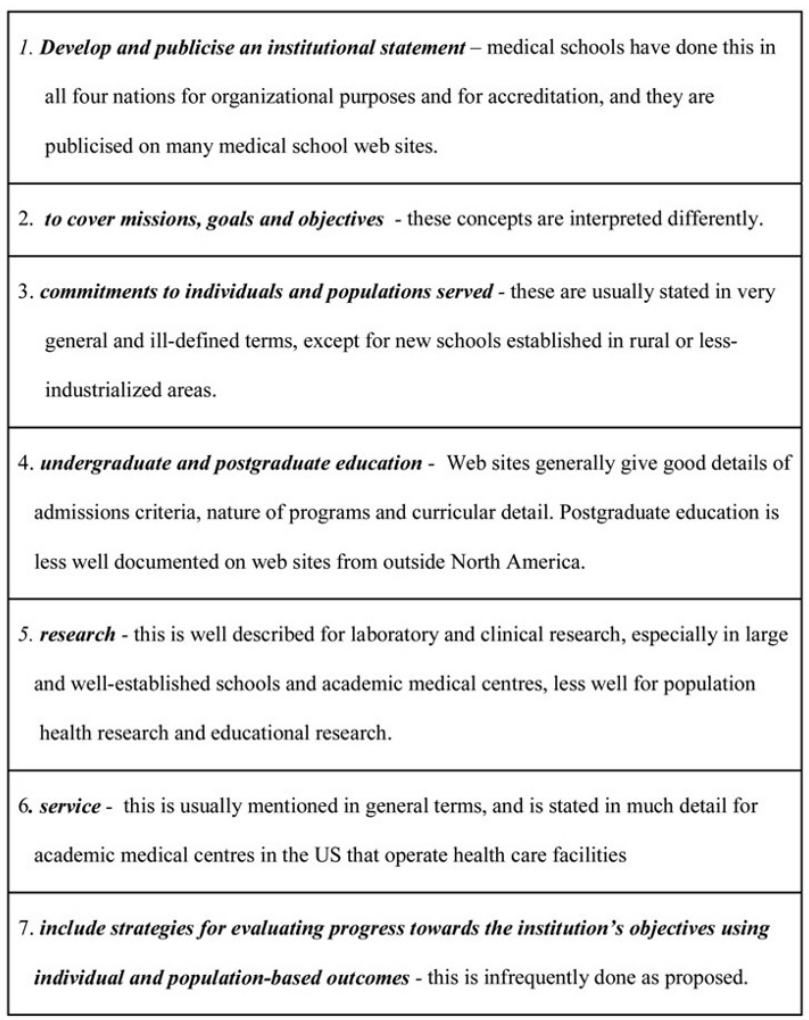

\section{Figure I}

RSM report [2] - proposals for medical school institutional statements of goals and objectives, annotated with observations from this study.

that medical academics should apply to their educational endeavors the sort of critical scientific thinking that is expected in their clinical and research work $[14,15]$.

Mission statements developed for businesses and health care $[11,16]$ are directed towards tangible products and services. For medical schools the "product" and the market are extremely complex. Here measurement of outcomes has to address intricate behaviors with many variables. It is very difficult to attribute specific physician competencies or health benefits for patients to particular segments of medical education, because of the multiple stages of medical school courses, postgraduate training and continuing medical education. Attribution of individual or group performance to their medical school's mission or objectives is even more tenuous. Nevertheless, there are useful outcome data that can be collected $[4,9]$. Frameworks have been proposed to evaluate the outcomes of revised and innovative curricula [17], and there are examples of data from graduate recollections and subjective opinions [18], and of educational outcome benefits [19].
It has been said that a socially responsible medical school perceives the needs of society and reacts accordingly, and a socially accountable school also consults society about priorities and provides evidence of impact of its deeds [20]. Fulfilment of the mission of serving the health needs of populations is a fundamental issue in social accountability of medical schools [21]. Three categories of assessment have been suggested in this regard planning or input, doing or activity, and impacting or output $[20,22]$. The most recently established medical schools with mandates to support health care for underserviced areas appear to have timely opportunities for prospective study of social accountability and population impact, in conjunction with their local health systems [23].

In considering the social accountability of medical schools there are several concepts that run in parallel with public accountability of health care systems. The advantages of standardization in public disclosure of health system outcomes include comparisons of the quality of care, comparisons of performance over time, amongst providers, and against defined standards of practice [24]. There are also potential disadvantages such as inappropriate focus on what is measured, and negative implications if results from different types of institution are compared in a competitive construct. This concern of potential misinterpretation of information is also applicable for medical schools because of the variability of their missions. Public presentation of medical school documentation should be done in a manner that makes clear the context of their objectives, community, traditions, and their institutional resources.

A rich store of information about the activities of medical schools is available on the Internet. This is a new resource base for the international medical community and a means to disseminate institutional values and ideas. The World Directory of Medical Schools includes 1647 schools in 157 countries [25]. Although all are listed as medical schools or medical colleges (and some have more elaborate titles in keeping with their many roles in addition to scholastic work) these are very heterogeneous organizations. It would be of value to have a general template for medical school mission statements placed on Web sites in the public domain. Because of differing interpretation of the concept of "mission" and "vision", these might be more appropriately called descriptive statements or profiles. The more general and prosaic the wording of the document, the more difficult is it to specify the measurable outcomes. Uniformity of content would therefore be helpful for reference, and in understanding the background or source of published work in international academic medicine, especially in medical education and population health. Figure 2 is a proposed 


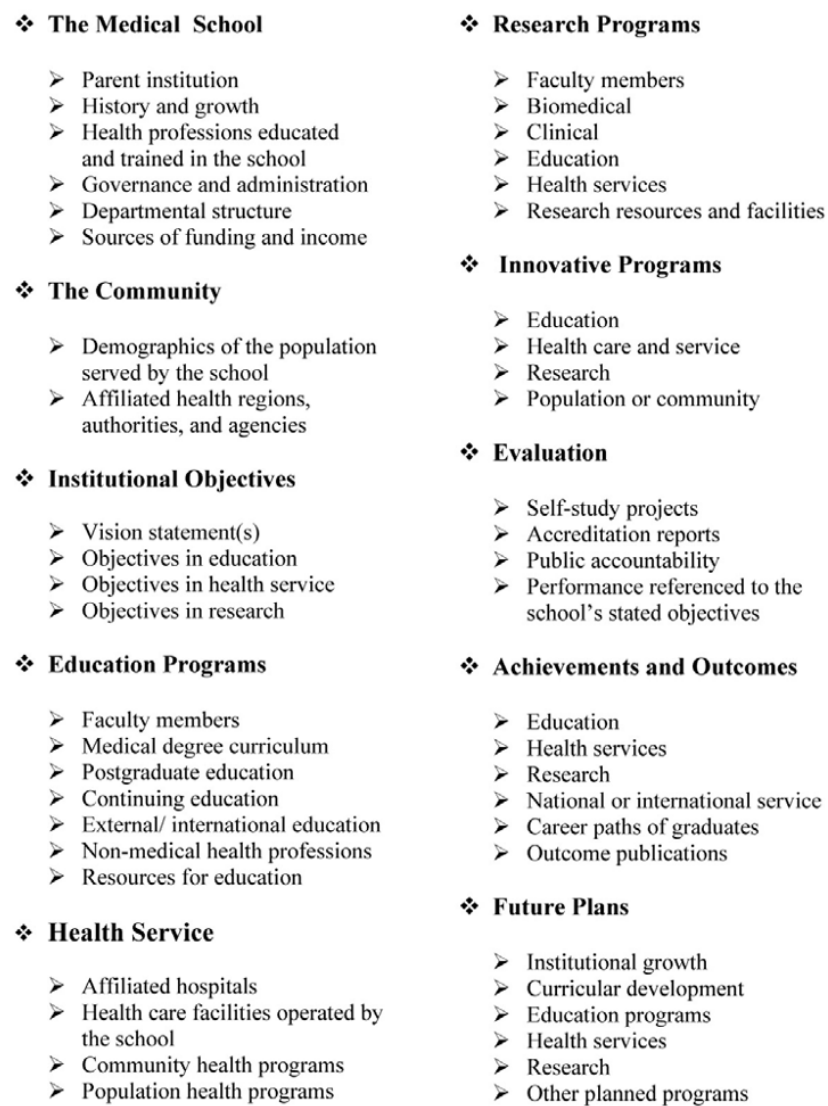

Figure 2

Generic web site template for medical school descriptive statements with main headings and sub-headings suitable for hypertext links.

generic template for the main headings and subheadings for medical school descriptive Web sites. The branched hierarchy hypertext capabilities of the Web permit links not only to appropriate sites in the same institution, but also to health system resources affiliated with the school, to the Web sites of medical school accrediting bodies, and to sites that provide general educational objectives [26]. Special or innovative programs that may be of interest to other schools can also be showcased, one example being the Web site of Dalhousie University Medical School, Canada [27].

It is acknowledged that several of the Internet documents abstracted for this article were not written to provide a comprehensive description of a medical school for external information. What was found in seeking statements consistent with the suggestions of the RSM report [2] was quite haphazard. Construction of a single Web portal to medical school descriptive statements, initially derived from the sources used in this study [3-8], could encourage consistency and enhance exchange of con- cepts and ideas in medical education and generally in international academic medicine.

\section{Summary}

Ten years ago medical schools were encouraged to develop and publicise mission documents describing their objectives and purpose. Assessment of institutional performance, including social accountability might then incorporate outcomes based on stated goals. Widespread adoption of Internet technology has enabled medical schools to showcase their work, and most of the web sites include variations on the concept of mission statements. This article draws attention to these web sites as a valuable repository of information about academic medical endeavours. It is suggested that inclusion of outcome and performance data within a standardised web-based framework would facilitate exchange of ideas and demonstrate how medical schools fulfil their missions.

\section{Competing Interests}

None declared

\section{Acknowledgment}

This work was done during a sabbatical leave in the Department of Health Care Education, University of Liverpool, England.

\section{References}

I. University of Aberdeen Medical School, Scotland [http:// w3.abdn.ac.uk/medicine/gmcdocument/al-2.shtml]

2. White KL, Connelly JE: The medical school's mission and the population's health. Ann Intern Med I99I, I I 5:968-972

3. Association of American Medical Colleges, Washington, USA. [http://pnet 400 .aamc.org/directories/schools/msalpha.cfm]

4. Liaison Council for Medical Education [http://www.lcme.org/]

5. Association of Canadian Medical Colleges [http://www.acmc.ca/can_fac.htm]

6. General Medical Council, London, UK [http://www.gmc-uk.org/ ]

7. Quality Assurance Agency for Higher Education, London, UK. [http://www.qaa.ac.uk/revreps/subjrev/byinstname.htm]

8. Australian Medical Council, Kingston, Australia [http://
[ www.amc.org.au/schools.asp]

9. Tomorrow's Doctors. Recommendations on Undergraduate Medical Education. London, U.K. : General Medical Council, 1993 [http://www.gmc-uk.org/med_ed/meded frameset.htm]

10. Canadian Post-MD Registry: Ottawa, Canada [http://www.caper.ca/]

II. Bart CK, Tambone JC: Mission statement rationales and organization alignment in the not-for-profit health care sector. Health Care Management Review 1998, 23:54-70

12. Reznick R: Does it matter where you go to medical school? Med Educ 1999, 33:557-558

13. A Snapshot of Medical Students' Education at the Beginning of the 2 I st Century: Reports from I 30 Schools. Acad Med 2000, 75:Sx-Sxiv

14. van der Vleuten CPM, Dolmans DHJ, Scherpbier AJ: The need for evidence in medical education. Medical Teacher 2000, 22:246-250

15. Holmes EW, Burks TF, Dzau V, Hindery MA, Jones RF, Kaye Cl, Korn D, Limbird LE, Marchase RB, Perlmutter R, et al: Measuring contributions to the research mission of medical schools. Acad Med 2000, 75:303-313

16. Forehand $\mathrm{A}$ : Mission and organizational performance in the healthcare industry. J Healthc Manag 2000, 45:267-277

17. Friedman CP, de Bliek R, Greer DS, Mennin SP, Norman GR, Sheps CG, Swanson DB, Woodward CA: Charting the winds of change: evaluating innovative medical curricula. Acad Med 1990, 65:814 
18. Lockwood JH, Danoff D, Whitcomb ME: The AAMC's 2000 graduate questionnaire. JAMA 2000, 284: 1080

19. Peters AS, Greenberger-Rosovsky R, Crowder C, Block SD, Moore GT: Long-term outcomes of the New Pathway Program at Harvard Medical School:a randomized controlled trial. Acad Med 2000, 75:470-479

20. Boelen C: Adapting health care institutions and medical schools to societies' needs. Acad Med I999, 74:SII-20

21. McCurdy L, Goode LD, Inui TS, Daugherty RM Jr, Wilson DE, Wallace AG, Weinstein BM, Copeland EM 3rd: Fulfilling the social contract between medical schools and the public. Acad Med 1997, 72:1063-1070

22. Peabody JW: Measuring the social responsiveness of medical schools: setting the standards. Acad Med 1999, 74:559-68

23. Lewkonia $R$ : The functional relationships of medical education and health care systems. Med Educ 2002

24. Marshall MN, Shekelle PG, Leatherman S, Brook RH: The public release of performance data: what do we expect to gain? A review of the evidence. JAMA 2000, I 2:1866-1874

25. World Directory of Medical Schools. 7th Edition. Geneva: World Health Organisation, 2000

26. AAMC Medical School Objectives Project. Washington: Association of American Medical Colleges, 1995-200 I [http:// www.aamc.org $/ \mathrm{meded} / \mathrm{msop} /]$

27. Innovative programs in medical education, medical research and patient care at Dalhousie Medical School, Nova Scotia, Canada. [http://www.medicine.dal.ca/home/innovprog/index.htm]

Publish with BioMed Central and every scientist can read your work free of charge

"BioMedcentral will be the most significant development for disseminating the results of biomedical research in our lifetime." Paul Nurse, Director-General, Imperial Cancer Research Fund

Publish with BMC and your research papers will be:

- available free of charge to the entire biomedical community

- peer reviewed and published immediately upon acceptance

- cited in PubMed and archived on PubMed Central

- yours - you keep the copyright
BioMedcentral.com editorial@biomedcentral.com 